\title{
Utilization of maternal health care services in post-conflict Nepal
}

\author{
This article was published in the following Dove Press journal: \\ International Journal of Women's Health \\ 25 August 2015 \\ Number of times this article has been viewed
}

\section{Tulsi Ram Bhandari \\ Prabhakaran Sankara Sarma Vellappillil Raman Kutty}

Achutha Menon Centre for Health Science Studies, Sree Chitra Tirunal Institute for Medical Sciences and Technology, Trivandrum, Kerala, India
Correspondence: Tulsi Ram Bhandari Achutha Menon Centre for Health Science Studies, Sree Chitra Tirunal Institute for Medical Sciences and Technology, Trivandrum, Thiruvananthapuram - 695011 , Kerala, India

Tel +9l 47| $2443 \mid 52$

Email tulsib2004@gmail.com
Background: Despite a decade-long armed conflict in Nepal, the country made progress in reducing maternal mortality and is on its way to achieve the Millennium Development Goal Five. This study aimed to assess the degree of the utilization of maternal health care services during and after the armed conflict in Nepal.

Methods: This study is based on Nepal Demographic and Health Survey data 2006 and 2011. The units of analysis were women who had given birth to at least one child in the past 5 years preceding the survey. First, we compared the utilization of maternal health care services of 2006 with that of 2011. Second, we merged the two data sets and applied logistic regression to distinguish whether the utilization of maternal health care services had improved after the peace process 2006 was underway.

Results: In 2011, 85\% of the women sought antenatal care at least once. Skilled health workers for delivery care assisted $36.1 \%$ of the women, and $46 \%$ of the women attended postnatal care visit at least once. These figures were $70 \%, 18.7 \%$, and $16 \%$, respectively, in 2006. Similarly, women were more likely to utilize antenatal care at least once (odds ratio $[\mathrm{OR}]=2.18$, confidence interval $[\mathrm{CI}]=1.95-2.43)$, skilled care at birth $(\mathrm{OR}=2.58, \mathrm{CI}=2.36-2.81)$, and postnatal care at least once $(\mathrm{OR}=4.13, \mathrm{CI}=3.75-4.50)$ in 2011.

Conclusion: The utilization of maternal health care services tended to increase continuously during both the armed conflict and the post-conflict period in Nepal. However, the increasing proportion of the utilization was higher after the Comprehensive Peace Process Agreement 2006.

Keywords: antenatal care, armed conflict, Nepal, post-conflict, postnatal care, skilled care at birth

\section{Introduction}

In 1990, a huge people's movement was followed by the advent of multiparty democracy, raising popular hopes for good governance and economic reforms. ${ }^{1,2}$ The absolute monarchy was converted into a constitutional monarchy. The major political parties upheld the parliamentary system and participated in the electoral process. ${ }^{3}$ A year later, in 1991, the first ever National Health Policy was announced and various health facilities were established to extend the access of health services at the community level. ${ }^{4}$

The very beginning of the parliamentary exercise was characterized by political disagreement among the parliamentary parties in Nepal. This resulted in political instability, increased sense of insecurity, and displacement of people along with obstruction of developmental activities, leading to economic setback. Emerging from the magnitude of dissatisfaction, the Communist Party of Nepal-Maoist (CPN-M) started an armed rebellion in 1996 professing radical political changes in the country. 
Initially, the movement started from the backward districts of Rolpa and Rukum in the Mid-Western Development Region and gradually extended throughout the country within 1 decade..$^{5-8}$

The armed conflict lasted from 1996 to $2006 . .^{5}$ The CPN-M came to control nearly $90 \%$ of the rural areas and formed their self-styled government known as the "People's Government", 5-8 under which they established their own courts, health facilities, strategic security stations, and so forth. They also started to closely monitor the governmental organizations and employees for regulating and ensuring the state's service delivery at the local level. ${ }^{5,6}$ Because of such dual pressure from the government and the Maoists, numerous health care workers and other government employees were displaced from rural areas, and local organizations were virtually rendered paralyzed. ${ }^{5,8}$ In the beginning of the movement, the government treated the CPN-M as a terrorist outfit and started insurgency operations to suppress the uprising. It was after years of war that the government and the international community realized and accepted the CPNM-led movement basically as a political problem. ${ }^{7,8}$ The major political parties and other power centers in Nepali politics accepted the demand for electing a Constituent Assembly to formulate a forward looking new constitution of Nepal. The decade-long Maoist uprising ended, and the "Comprehensive Peace Process Agreement" was signed between the government and the CPN-M that brought the CPN-M in the mainstream politics in $2006 .^{8-11}$

Proper utilization of health care services requires an environment of adequate security, and naturally, pregnant women, lactating mothers, adolescent girls, and children happen to be hard-hit in any armed conflict as they are the vulnerable groups who require timely health care services. ${ }^{12}$ In 2001 , the government ordered all health professionals to report to the security officials immediately about any war injuries they had treated. ${ }^{7}$ Many health professionals were bound to be displaced; some were abducted and even killed, and many local health facilities were eventually destroyed. ${ }^{13,14}$

Most of the specialized health facilities in Nepal are located in the Kathmandu valley and other regional cities. During the armed conflict, the government machinery could only focus on the capital city and other urban areas; hence, rural and remote parts were seemingly governed by the People's Government running parallel. ${ }^{14,15}$ Despite the long conflict and partially paralyzed government machinery, health indicators seemed to improve continuously in Nepal. Some studies even claim that the Maoist movement had essentially a positive effect as far as the regulation of the community-level health services were concerned, simply because they were better at making sure that the health staff got to their work. ${ }^{11,15}$

Nepal made some extent of progress in reducing the high rate of maternal mortality along with the improvement in other indicators during the violent conflict period from 1996 to 2006. The maternal mortality ratio of Nepal was 539 in 1996, 415 in 2001, 281 in 2006, and 229 in 2011. The other indicators like antenatal care, delivery care, and postnatal care also showed signs of improvement during the armed conflict. ${ }^{4,11,16,17}$ This progress strongly raises a question whether the armed conflict hindered or facilitated the utilization of health care services. This study aimed to assess the degree of the utilization of maternal health care services during and after the armed conflict in Nepal.

\section{Materials and methods Source of data}

This study is based on the secondary analysis of the Nepal Demographic and Health Survey (NDHS) data 2006 and 2011. The Demographic and Health Survey Program permitted access to the data for further use. Both surveys were national representative population-based household surveys, which collected and processed the information on various health indicators. The NDHS is an international standard survey carried out in developing countries and is supported by the Center for Disease Control and Prevention. The areas covered by both the surveys were almost the same; ie, they focused mainly on fertility, family planning, infant mortality, and child mortality. In the same way, they focused on adult mortality, maternal mortality, maternal and child health, nutrition, and knowledge of HIV/AIDS and other sexually transmitted infections. But the primary objectives of the surveys were different in that the NDHS 2006 primarily intended to furnish policy makers and planners with detailed information, whereas the NDHS 2011 mainly purported to provide estimates with an acceptable level of precision on the aforementioned study areas. ${ }^{16,17}$

\section{Brief description of survey}

A single sampling frame for both the NDHS 2006 and NDHS 2011 was used with the same list of census enumeration areas, with population and household information from the National Population Census 2001 of Nepal. By considering the time gap and population dynamics, the sample size was adjusted through quick counting of households at the first stage of sampling for the NDHS 2011. Each of the 75 districts of Nepal was subdivided into village development 
committees and/or municipalities, and each village development committee and municipality was further divided into wards. The primary sampling unit (PSU) for both surveys was a ward, a sub-ward, or a group of wards in rural areas and a sub-ward in urban areas.

The samples of both the surveys were based on two-stage stratified national representative samples of households. At the first stage of sampling, 82 PSUs from the urban areas and 178 PSUs from the rural areas were selected in 2006, while 95 PSUs from the urban areas and 194 PSUs from the rural areas were selected in 2011, using systematic random sampling with probability proportional to size. At the second stage of sampling, 30 households per PSU in the urban areas and 36 households per PSU in the rural areas were selected in 2006, and 35 households per PSU in the urban areas and 40 households per PSU in the rural areas were selected in 2011, using systematic random sampling method. In total, 10,793 women in NDHS 2006 and 13,485 women in NDHS 2011 were interviewed to collect the required information. ${ }^{16,17}$

\section{Predictors and outcome variables}

Maternal health care includes all antenatal, intra-natal, and postnatal cares. Quality care is critical to achieve the aim of both healthy mother and a healthy baby at the end of pregnancy. ${ }^{18}$ The NDHS covers various aspects of the maternal health care services. We have chosen the proportions of at least one antenatal care visit, delivery care attended by skilled birth attendants, and at least one postnatal care visit as outcome variables and survey years 2006 and 2011 as explanatory variables to assess the utilization of maternal health care services. We considered all auxiliary nurse midwives, nurses, and medical doctors as skilled birth attendants who were trained in safe delivery care. Assessment was based on the considerations of development regions, ecological zones, locations of residence, and education of the mother along with the economic status of the family, age of the mother, and birth order of the most recent delivery. We furthermore assessed the utilization status of maternal health care services in terms of the broad geographical and political divisions of the country. All the five development regions were regrouped into two regions, ie, Far and Mid-Western Region into one and the whole of the Eastern, Central, and Western Region into another, for comparing the average utilization proportions regarding at least one antenatal care visit, skilled care at birth, and at least one postnatal care visit between the two regions. Initially, the Mid-Western and Far-Western Development Regions seemed to have been more affected by the armed conflict. ${ }^{1,6,7}$ The Comprehensive Peace Process
Agreement year 2006 has been taken as a cutoff point for assessing the utilization of maternal health care services during and after the armed conflict in Nepal.

\section{Statistical analysis}

The units of analysis of this study were the women who had given birth to at least one child in the past 5 years preceding the surveys. First, we computed the descriptive statistics from the NDHS data 2006 and 2011 separately to compare the proportions of maternal health care utilization in the two survey periods. Second, we merged the two data files into one with an added dummy variable (period) to indicate the years of the study. We compared the utilization of maternal health care services (at least one antenatal care visit, skilled care at birth, and at least one postnatal visit) between the two periods. For this purpose, we built a regression model (Model I) with period as the single predictor for the utilization of maternal health care services. Then, we added other variables of development regions, ecological zones, and places of residence to build Model II by considering the origin and extension of the armed conflict from two hilly districts of the Mid-Western Development Region to other hilly and mountainous districts, plain land, and the rural parts of the country. ${ }^{16,17}$ The Maoist movement was strategically successful in drawing public attention to the existing wider socioeconomic inequalities through revolutionary slogans for radical changes of the political system. ${ }^{19-21}$ Therefore, we further added socioeconomic and demographic factors including geophysical components and built Model III. For assessing these three outcome variables, we built three models of each outcome variable, ie, antenatal care, delivery care, and postnatal care, separately.

\section{Results Antenatal care}

The NDHS 2011 showed that nearly $85 \%$ of the women who were interviewed sought at least one antenatal care during their most recent pregnancy in the past 5 years preceding the survey. A total of $62 \%$ of the women received care from skilled providers, ie, doctors, nurses, and auxiliary nurse midwives, and more than $20 \%$ of the women received care from general health workers, not trained particularly in pregnancy care. Nearly $60 \%$ of the women started antenatal care in the first trimester and visited health facilities four or more times for their antenatal care. These figures were considerably less in 2006 when $70 \%$ of the women sought antenatal care at least once during their most recent pregnancy in the past 5 years preceding the survey. In 2006, not more than 50\% of 
the women received care from skilled providers like doctors, nurses, and midwives, and nearly $25 \%$ of the women received such care from general health workers. Almost $40 \%$ of the women started antenatal care in the first trimester and visited health facilities four or more times. The utilization proportion of antenatal care varied among the strata such as development and ecological regions, residence locations, and socioeconomic and demographic characteristics of women (Table 1). The increased proportion of the utilization of antenatal care service at least once is higher in the Far-Mid-Western Development (FMWD) Region than in the Eastern-Central-Western Development (ECWD) Region (Figure 1). Women were more likely to get antenatal care at least once (odds ratio $[\mathrm{OR}]=2.18$, confidence interval $[\mathrm{CI}]=1.95-2.43$ ) in 2011 (Table 2).

\section{Delivery care}

The proportions of skilled care at birth and institutional delivery in 2011 increased nearly twofold compared with

Table I Utilization of maternal health care services in Nepal with reference to selected predictors (figures in \%)

\begin{tabular}{|c|c|c|c|c|c|c|c|c|c|c|c|c|}
\hline \multirow[t]{3}{*}{ Predictors } & \multicolumn{6}{|l|}{2006} & \multicolumn{6}{|c|}{2011} \\
\hline & \multicolumn{2}{|c|}{$\begin{array}{l}\text { At least } \\
\text { one ANC } \\
(n=4,182)\end{array}$} & \multicolumn{2}{|c|}{$\begin{array}{l}\text { Delivery } \\
\text { assisted } \\
\text { by SBA } \\
(n=5,783)\end{array}$} & \multicolumn{2}{|c|}{$\begin{array}{l}\text { At least } \\
\text { one PNC } \\
(n=4,930)\end{array}$} & \multicolumn{2}{|c|}{$\begin{array}{l}\text { At least } \\
\text { one ANC } \\
(n=4,079)\end{array}$} & \multicolumn{2}{|c|}{$\begin{array}{l}\text { Delivery } \\
\text { assisted } \\
\text { by SBA } \\
(n=5,306)\end{array}$} & \multicolumn{2}{|c|}{$\begin{array}{l}\text { At least } \\
\text { PNC } \\
(n=4,079)\end{array}$} \\
\hline & $\%$ & $P$-value & $\%$ & $P$-value & $\%$ & $P$-value & $\%$ & $P$-value & $\%$ & $P$-value & $\%$ & $P$-value \\
\hline Development regions & & $<0.001$ & & $<0.001$ & & $<0.001$ & & $<0.001$ & & $<0.001$ & & $<0.001$ \\
\hline East & 77.5 & & 17.9 & & 12.9 & & 86.7 & & 38.2 & & 42.3 & \\
\hline Central & 74.1 & & 23.2 & & 30.7 & & 83.3 & & 39.4 & & 44.6 & \\
\hline West & 69.9 & & 23.1 & & 17.0 & & 88.3 & & 45.5 & & 51.8 & \\
\hline Mid-west & 63.3 & & 13.8 & & 9.0 & & 79.8 & & 31.2 & & 40.1 & \\
\hline Far-west & 70.2 & & 12.4 & & 7.4 & & 88.3 & & 31.8 & & 42.6 & \\
\hline Total & 72.2 & & 18.4 & & 15.9 & & 85.0 & & 36.8 & & 43.8 & \\
\hline Ecological zones & & $<0.001$ & & $<0.001$ & & $<0.001$ & & $<0.001$ & & $<0.001$ & & $<0.001$ \\
\hline Mountain & 60.8 & & 9.7 & & 5.3 & & 79.0 & & 20.6 & & 28.0 & \\
\hline Hill & 67.3 & & 19.6 & & 6.1 & & 81.6 & & 32.3 & & 40.0 & \\
\hline Terai & 79.9 & & 20.2 & & 27.9 & & 91 & & 48.8 & & 54.6 & \\
\hline Total & 72.2 & & 18.4 & & 15.9 & & 85.0 & & 36.8 & & 43.8 & \\
\hline Residences & & $<0.001$ & & $<0.001$ & & & & $<0.001$ & & $<0.001$ & & $<0.001$ \\
\hline Urban & 85.5 & & 40.7 & & 13.8 & & 93.1 & & 67.7 & & 68 & \\
\hline Rural & 68.1 & & 11.9 & & 16.3 & & 82.7 & & 28.7 & & 37 & \\
\hline Total & 72.2 & & 18.4 & & 15.9 & & 85.0 & & 36.8 & & 43.8 & \\
\hline Education of respondent & & $<0.001$ & & $<0.001$ & & $<0.001$ & & $<0.001$ & & $<0.001$ & & $<0.001$ \\
\hline Illiterate & 61.2 & & 8.0 & & 15.2 & & 74.4 & & 18.7 & & 25.4 & \\
\hline Primary & 80.5 & & 18.1 & & 12.4 & & 87.3 & & 34.3 & & 41.7 & \\
\hline Secondary & 92.5 & & 43.5 & & 19.3 & & 95.5 & & 58.8 & & 62.0 & \\
\hline$\geq \mathrm{SLC}$ & 100 & & 82.5 & & 43.5 & & 99.6 & & 86.0 & & 87.5 & \\
\hline Total & 72.2 & & 18.4 & & 15.9 & & 85.0 & & 36.8 & & 43.8 & \\
\hline Wealth quintile & & $<0.001$ & & $<0.001$ & & $<0.001$ & & $<0.001$ & & $<0.001$ & & $<0.001$ \\
\hline Lowest & 50.2 & & 4.3 & & 6.2 & & 69.3 & & 12.7 & & 19.4 & \\
\hline Second & 68.9 & & 10.5 & & 18.4 & & 83.2 & & 24.4 & & 32.2 & \\
\hline Middle & 76.3 & & 12.5 & & 21.8 & & 91.5 & & 38.4 & & 46.7 & \\
\hline Fourth & 84.9 & & 23.7 & & 22.3 & & 94.4 & & 57.1 & & 60.7 & \\
\hline Highest & 93.5 & & 58.4 & & 20.4 & & 97.4 & & 82.4 & & 80.3 & \\
\hline Total & 72.2 & & 18.4 & & 15.9 & & 85.0 & & 36.8 & & 43.8 & \\
\hline Age of respondent & & $<0.001$ & & $<0.001$ & & $<0.001$ & & $<0.001$ & & $<0.001$ & & $<0.001$ \\
\hline$<20$ years & 82.9 & & 27.9 & & 14.1 & & 92.8 & & 51.1 & & 52.6 & \\
\hline 20-34 years & 75.2 & & 19.2 & & 17 & & 87.4 & & 38.4 & & 45.8 & \\
\hline$\geq 35$ years & 49.8 & & 9.1 & & 10.2 & & 65.1 & & 17.5 & & 25.8 & \\
\hline Total & 72.2 & & 18.4 & & 15.9 & & 85.0 & & 36.8 & & 43.8 & \\
\hline Birth order & & $<0.001$ & & $<0.001$ & & $<0.01$ & & $<0.001$ & & $<0.001$ & & $<0.001$ \\
\hline Ist & 84.3 & & 33.3 & & 17.8 & & 94.6 & & 55.4 & & 61.7 & \\
\hline 2 nd or $3 r d$ & 75.6 & & 15.8 & & 16.1 & & 87.9 & & 33.7 & & 43.4 & \\
\hline 4 th or 5 th & 64.2 & & 7.1 & & 16.0 & & 75.1 & & 18.6 & & 25.1 & \\
\hline 6th or above & 45.2 & & 6.0 & & 10.7 & & 52.7 & & 10.0 & & 15.8 & \\
\hline Total & 72.2 & & 18.4 & & 15.9 & & 85.0 & & 36.8 & & 43.8 & \\
\hline
\end{tabular}

Abbreviations: ANC, antenatal care; SBA, skilled birth attendants; PNC, postnatal care; SLC, school leaving certificate. 


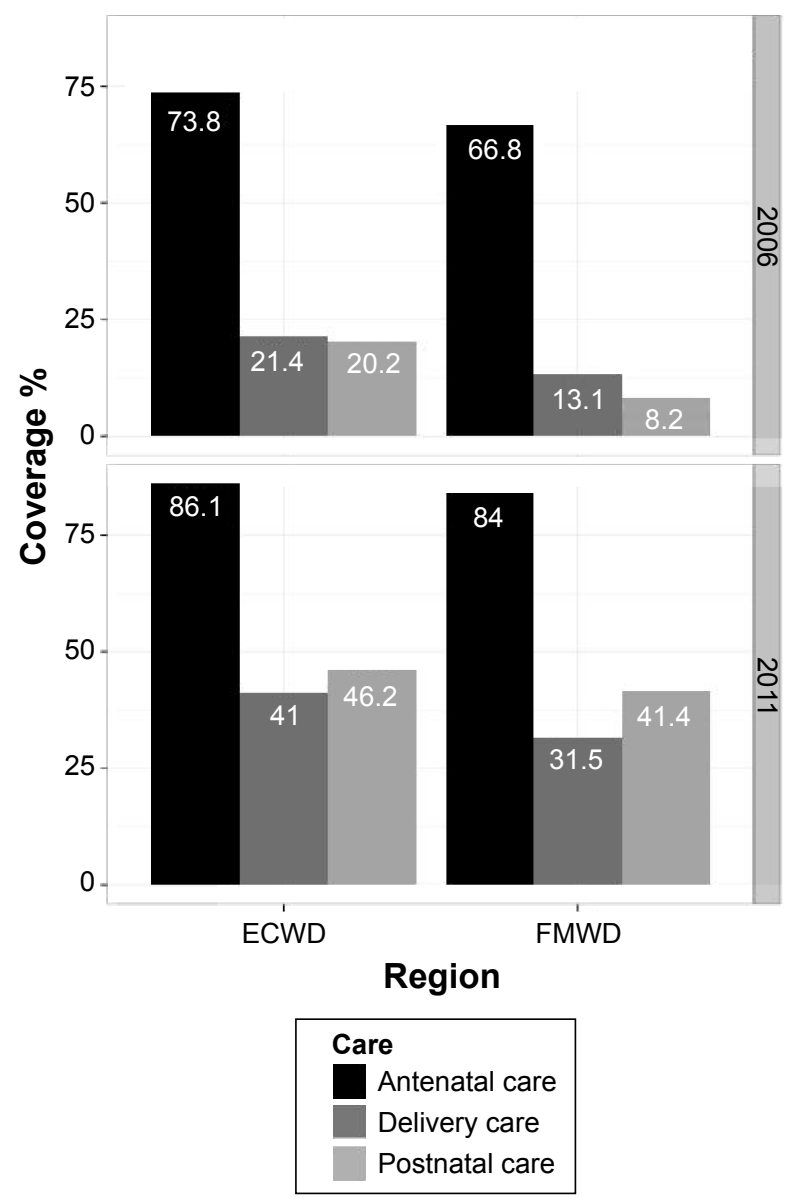

Figure I Maternal health care service utilization status in Nepal in percentage with comparisons between the years 2006 and 2011 region-wise.

Abbreviations: ECWD, Eastern-Central-Western Development; FMWD, FarMid-Western Development.

those of 2006 . They reached $36.1 \%$ and $35.3 \%$, respectively, in 2011, while these figures were just $18.7 \%$ and $17.8 \%$, respectively, in 2006. These figures varied among the strata such as development and ecological regions, residence locations, and socioeconomic and demographic characteristics of the concerned women (Table 1). The increased proportion of the utilization of skilled care service at birth was almost the same in the FMWD and the ECWD Regions (Figure 1). Women were more likely to utilize skilled care at birth $(\mathrm{OR}=2.58, \mathrm{CI}=2.36-2.81)$ in 2011 (Table 2).

\section{Postnatal care}

According to the NDHS 2011, 46\% of the women sought at least one postnatal care after their most recent delivery in the past 5 years preceding the survey. Out of the total postnatal care receivers, $53 \%$ of the women received care from the skilled providers, and the rest received the same from general health workers. More than half of the women sought postnatal care within 24 hours of the delivery. The utilization of postnatal care was relatively less in 2006 when $16 \%$ of the women had sought postnatal care at least once. Out of the total postnatal care receivers, $67.8 \%$ of the women received care from skilled providers, the rest were examined and treated by general health workers, and more than half of the women received postnatal care within the first 24 hours of the delivery. The utilization proportion of postnatal care varied among the strata such as development and ecological regions, residence locations, and socioeconomic and demographic characteristics (Table 1). The proportion of the utilization of postnatal care service at least once was higher in the FMWD Region than in the ECWD Region (Figure 1). Women were more likely to utilize postnatal care at least once $(\mathrm{OR}=4.13, \mathrm{CI}=3.75-4.50)$ in 2011 (Table 2).

\section{Discussion}

The purpose of this study was to compare the utilization of maternal health care services in post-conflict Nepal with regard to the armed conflict period. We found continuous improvement in the utilization of maternal health care

Table 2 Association of period (2006 and 201 I), development regions, ecological zones, place of residence, and socioeconomic strata with utilization of maternal health care services in Nepal

\begin{tabular}{|c|c|c|c|c|c|c|c|c|c|}
\hline \multirow[t]{3}{*}{ Models } & \multicolumn{3}{|c|}{$\begin{array}{l}\text { At least one antenatal } \\
\text { care visit }\end{array}$} & \multicolumn{3}{|c|}{ Skilled care at birth } & \multicolumn{3}{|c|}{$\begin{array}{l}\text { At least one postnatal } \\
\text { care visit }\end{array}$} \\
\hline & \multirow[t]{2}{*}{ OR } & \multicolumn{2}{|c|}{ 95\% Cl for OR } & \multirow[t]{2}{*}{ OR } & \multicolumn{2}{|c|}{ 95\% $\mathrm{Cl}$ for $\mathrm{OR}$} & \multirow[t]{2}{*}{ OR } & \multicolumn{2}{|c|}{ 95\% Cl for OR } \\
\hline & & Lower & Upper & & Lower & Upper & & Lower & Upper \\
\hline Period* & 2.2 & 2.0 & 2.4 & 2.6 & 2.4 & 2.8 & 4.1 & 3.7 & 4.6 \\
\hline $\begin{array}{l}\text { Period adjusted for the development } \\
\text { regions, ecological zones, and residences** }\end{array}$ & 2.4 & 2.2 & 2.7 & 3.3 & 3.0 & 3.6 & 4.9 & 4.4 & 5.4 \\
\hline $\begin{array}{l}\text { Period adjusted for the development regions, } \\
\text { ecological zones, places of residence, education, } \\
\text { wealth, age of women and birth order*** }\end{array}$ & 2.3 & 2.0 & 2.6 & 3.2 & 2.9 & 3.6 & 3.9 & 3.5 & 4.4 \\
\hline
\end{tabular}

Notes: *Model I: period and utilization of maternal health care services; **Model II: period, development regions, ecological zones, residences, and utilization of maternal health care services; ***Model III: period, development regions, ecological zones, residences, education, wealth, age of women, birth order, and utilization of maternal health care services.

Abbreviations: $\mathrm{Cl}$, confidence interval; $\mathrm{OR}$, odds ratio. 
services throughout the armed conflict period as well as the post-conflict period. However, the utilization proportion of maternal health care services was found higher in the postconflict period.

We wanted to explore whether period had any influence on the utilization of maternal health care services independently or in terms of development regions, ecological zones, place of residence, and demographic and socioeconomic factors. We found that the utilization differed in terms of development regions, ecological zones, place of residence, and socioeconomic strata. When we adjusted the period to development regions, ecological zones, and place of residence in models, the odds ratios of the utilization proportions of antenatal care at least once, skilled care at birth, and postnatal care at least once were increased by $9.1 \%$, $26.92 \%$, and $19.51 \%$, respectively. Similarly, when period was adjusted to development regions, ecological zones, and places of residence together with demographic and socioeconomic factors, the odds ratios of the utilization increased by $4.50 \%, 23.10 \%$, and $-4.85 \%$, respectively. Women from the ECWD Region, plains and the urban areas, and those with better educational and economic status tended to have a positive association with the utilization of maternal health care services. It indicates that the overall utilization status was increased in 2011 compared with that of the 2006. However, it varied in terms of development regions, ecological zones, places of residence, and socioeconomic strata.

There was no unanimous view among researchers as to whether the Maoist movement had a positive or a negative effect on the health care system of Nepal. Prior studies reveal a paradoxical effect of armed conflict in the health care system of Nepal. Some studies show that the armed conflict destroyed many physical infrastructures, displaced and killed many health workers, and contributed to the suffering of the poor and marginalized people and hence health services were obstructed largely at the primary health care level. ${ }^{7,13,14}$ Some other studies state that the Maoist activists and the People's Government monitored the primary health care services closely in the Maoist-affected areas, which essentially favored better health performance at the primary health care level. ${ }^{5,11,15}$

In Nepal, nearly three-fourths of women in urban areas, one-thirds in semi-urban areas, and one-fifth in rural areas attended health facilities for their delivery from 2006 to 2011. ${ }^{16,17}$ Prior studies have raised a question whether the progress made between 2006 and 2011 with respect to maternal health care was the effect of the Comprehensive Peace Process itself or an outcome of the efforts of government and other supporting agencies. ${ }^{11,14,15}$ After entering mainstream politics, the CPN-M formed the government and introduced their "New Nepal, Healthy Nepal" program and announced free maternity care, a transportation subsidy scheme, and other incentives for mothers delivering their baby at recommended health facilities through the Ama Surakchhya Karyakram (safe delivery care program) in 2009. .2-24 $^{2}$

The popular programs were continued by the subsequent governments in course of achieving the Millennium Development Goal Five. The country devised and focused programs targeting the Millennium Development Goal and launched additional incentives to increase the utilization of maternal health care services. ${ }^{23,24}$ The succeeding governments and international community observed:

[...] much attention in post conflict peace building focuses on

the political process; fulfilling public health objectives may

very well be the key to successful peace building $[\ldots]^{23}$

which reflects a major role of the peace process agreement to enhance the health care system in the country.

The epidemiologic transition theory focuses on health and disease patterns and their demographic, economic, and social determinants and consequences. Any armed conflict with all its ill-effects hits the most vulnerable groups hard, especially children, pregnant women, lactating mothers, and elderly population. ${ }^{25,26}$ We objectively studied the ill-effects of the Nepali armed conflict on the utilization of maternal health care services, based on the geographical diversities and political divisions of the country. Initially, the armed conflict had started from the hilly and mountainous areas of the Mid-Western Development Region and gradually spread throughout the country within 1 decade. ${ }^{5-8}$ By controlling the period, we found that the Mid-Western and Far-Western Development Region, mountainous and hilly districts, and most of the rural areas were less likely to utilize the maternal health care services before the Comprehensive Peace Process Agreement of 2006. After the peace process started, considerable improvement on the utilization of maternal health care services is well evident, although the utilization rate was still relatively less in the hilly and mountainous areas.

The utilization of maternal health care services is, to some extent, determined by social environment. For addressing the health care needs of the conflict-affected people, health care providers are required to revise the existing health strategies, which may include decentralization of services, maintaining neutrality among factions, and strengthening community-based health care services. ${ }^{13,22,27} \mathrm{We}$ found that 
the period was of significance with regards to maternal health care utilization outcomes. Even after the adjustment of the socioeconomic and demographic variables such as women's age, education, and birth order and family economy with the period, the utilization of maternal health care services was still found significant. The wealthy and educated women were more likely to utilize maternal health care services even in the extremely Maoist-affected areas.

The utilization of maternal health care services depends upon various factors, ie, geophysical conditions, socioeconomic environment and demographic characteristics. Similarly, development regions, ecological zones, places of residence, educational status of the women, household economic condition, their age, and the order of the most recent pregnancy were found to be major predictors of the utilization of maternal health care services in Nepal. ${ }^{27-30}$ Our analysis shows similar findings and furthermore explores that the Comprehensive Peace Process Agreement 2006 and the subsequent efforts had positive effect on the utilization of maternal health care services in Nepal.

This analysis is based on secondary data, which were obtained from the two cross-sectional Nepal Demographic Health Surveys 2006 and 2011. During the NDHS 2006 period, the entire health care system of the nation was badly affected by a decade-long armed conflict as the state machinery itself was in a semi-paralyzed condition. Despite being a nationallevel survey, the DHS survey 2006 was partially affected by the armed conflict in most of the remote and rural areas. ${ }^{16}$ Similarly, despite the bulks of maternal health care components, we selected only three outcome variables, ie, at least one antenatal care, skilled care at birth, and at least one postnatal care. This study concentrated purely on the quantitative dimensions of maternal health care services for comparing the utilization situation before and after the Comprehensive Peace Process in Nepal. We suggest more independent quantitative as well as qualitative studies for the precise validation of the progress and role of the Comprehensive Peace Process in the utilization of maternal health care services in Nepal.

\section{Conclusion}

Most indicators of the maternal health care services were found to have been positively affected during the armed conflict as well as in the post-conflict Nepal. However, the utilization of maternal health care services was low in rural and remote parts of Nepal until 2011. There was variability in the progress patterns within and between the development regions, ecological zones, and socioeconomic strata. The proportion of the utilization of maternal health care services was remarkably high in the armed conflict areas in 2011 compared with that of 2006. It is significantly indicated that the Comprehensive Peace Process Agreement 2006 has a positive influence in the utilization of maternal health care services in post-conflict Nepal.

\section{Acknowledgments}

The authors express sincere gratitude to the Demographic and Health Surveys Program, ICF International, USA, for permitting access to the data for further use. They also thank professional English Language Editor Mr Babulal Bhandari, Sarashwati College, Tokha Kathmandu, Nepal, for the editing services of this article. The authors used Nepal Demographic Surveys data 2006 and 2011, which are free to access.

\section{Author contributions}

VRK and TRB conceived the idea of the article. TRB requested the Demographic and Health Surveys Program, ICF International, USA, for permitting access to the data. After having access to the data, all authors contributed toward data analysis, drafting and critically revising the paper and agree to be accountable for all aspects of the work.

\section{Disclosure}

The authors disclose no receipt of any of the financial support for the research, authorship, or publication of this article and further report no conflicts of interest in this work.

\section{References}

1. Singh S. Impact of long-term political conflict on population health in Nepal. Can Med Assoc J. 2004;171:1499-1501.

2. Hutt M. Himalayan People's War: Nepal's Maoist Rebellion. Bloomington: Indiana University Press; 2004.

3. Grover V. Nepal: Government and Politics. New Delhi: Deep and Deep Publications; 2000.

4. Bhandari TR, Dangal G. Maternal mortality: paradigm shift in Nepal N J Obstet Gynaecol. 2012;7:3-8.

5. Devkota B, van Teijlingen ER. Politicians in apron: case study of rebel health services in Nepal. Asia Pac J Public Health. 2009;21: 377-384.

6. Do Q-T, Iyer L. Geography, poverty and conflict in Nepal. $J$ Peace Res. 2010;47:735-748.

7. Ghimire SK. An interconnection of armed conflict and health service system in Rolpa district of Nepal. Soc Med. 2009;4:139-147.

8. Nepal M, Bohara AK, Gawande K. More inequality, more killings: the Maoist insurgency in Nepal. Am J Polit Sci. 2011;55:886-906.

9. Shneiderman SB. The formation of political consciousness in rural Nepal. Dialect Anthropol. 2009;33:287-308.

10. Ghimire S. Euphoria Versus Sufferings: Revolutionary Rolpa in Post Conflict Context; 2011. Available from: http://nepalpolicynet.com/ images/NewAngle/Vol1/8_Ghimire_Revolutionary\%20Rolpa $\% 20$ in $\% 20$ post $\% 20$ conflict $\% 20$ context.pdf. Accessed May 10, 2014 May 15, 2014

11. Devkota B, van Teijlingen ER. Understanding effects of armed conflict on health outcomes: the case of Nepal. Confl Health. 2010;4:20. 
12. Southall D. Armed conflict women and girls who are pregnant, infants and children; a neglected public health challenge. What can health professionals do? Early Hum Dev. 2011;87:735-742.

13. Stevenson PC. Kathmandu high-risk medical care in war-torn Nepal. Lancet. 2002;359:1495.

14. Ghimire LV, Pun M. Health effects of Maoist insurgency in Nepal. Lancet. 2006;368:1494.

15. Collins S. Assessing the health implications of Nepal's ceasefire. Lancet. 2006;368:907-908.

16. Ministry of Health and Population Nepal, New ERA and Macro International Inc. Nepal Demographic and Health Survey 2006. Kathmandu, Nepal: Ministry of Health and Population; New ERA and Macro International, Inc.; 2007.

17. Ministry of Health and Population Nepal, New ERA and Macro International Inc. Nepal Demographic and Health Survey 2011. Kathmandu, Nepal: Ministry of Health and Population; Calverton, MD: New ERA and ICF International, Inc.; 2012.

18. Bhandari TR. Maternal and child health situation in South East Asia. N J Obstet Gynaecol. 2012;7:5-10.

19. Basnett Y. From politicization of grievances to political violence: an analysis of the Maoist movement in Nepal. Dev Stud Inst Lond Sch Econ Polit Sci. 2009; 7:1-33.

20. Bohara AK, Mitchell NJ, Nepal M. Opportunity, democracy, and the exchange of political violence a sub-national analysis of conflict in Nepal. J Confl Resolut. 2006;50:108-128.

21. Tiwari BN. An assessment of the causes of conflict in Nepal. The Maoist Insurgency Nepal: Revolution in the Twenty-First Century. 2009; 20:241.
22. Price JI, Bohara AK. Maternal health care amid political unrest: the effect of armed conflict on antenatal care utilization in Nepal. Health Policy Plan. 2013;28(3):309-319.

23. Tsai TC. Public health and peace building in Nepal. Lancet. 2009;374: 515-516.

24. Choulagai B, Onta S, Subedi N, et al. Barriers to using skilled birth attendants' services in mid- and far-western Nepal: a cross-sectional study. BMC Int Health Hum Rights. 2013;13:49.

25. Omran AR. The epidemiologic transition: a theory of the epidemiology of population change. Milbank Mem Fund Q. 1971;49(4):509-538.

26. Albertyn R, Bickler SW, Van As AB, Millar AJW, Rode H. The effects of war on children in Africa. Pediatr Surg Int. 2003;19:227-232.

27. Jordans MJ, Tol WA, Susanty D, et al. Implementation of a mental health care package for children in areas of armed conflict: a case study from Burundi, Indonesia, Nepal, Sri Lanka, and Sudan. PLoS Med. 2013;10:e1001371.

28. Joshi C, Torvaldsen S, Hodgson R, Hayen A. Factors associated with the use and quality of antenatal care in Nepal: a population-based study using the demographic and health survey data. BMC Pregnancy Childbirth. 2014;14:94.

29. Neupane S, Doku D. Utilization of postnatal care among Nepalese women. Matern Child Health J. 2013;17:1922-1930.

30. Furuta M, Salway S. Women's position within the household as a determinant of maternal health care use in Nepal. Int Fam Plan Perspect. 2006;32(1):17-27.
International Journal of Women's Health

\section{Publish your work in this journal}

The International Journal of Women's Health is an international, peerreviewed open-access journal publishing original research, reports, editorials, reviews and commentaries on all aspects of women's healthcare including gynecology, obstetrics, and breast cancer. The manuscript management system is completely online and includes

\section{Dovepress}

a very quick and fair peer-review system, which is all easy to use. Visit http://www.dovepress.com/testimonials.php to read real quotes from published authors. 